\title{
The Role of Internal and External Motivation on Employee Performance
}

\author{
Mohammed Matar, Aldhaheri, Mohammed Nussari
}

\begin{abstract}
This study employs structural equations modeling via PLS to analyze the 732 valid questionnaires in order to assess the proposed model that is based on the organizational motivation characteristics to identify its effect on the performance of employees in the government sector in Dubai. The main independent constructs in the model are intrinsic motivation and external motivation. The dependent construct is employee performance. The study will describe relations among the various constructs. Our work has improved our insight in the importance of organizational motivation. Results indicated that both independent variables significantly predicted employee performance with a various percentage. The proposed model explained $37.7 \%$ of the variance in employee performance.
\end{abstract}

Keywords : Intrinsic motivation; extrinsic motivation; employee performance; Dubai.

\section{INTRODUCTION}

Due to the transformation of external and internal environments of public organizations recently. There is increasing amount of stress that employees in public sector are enduring about the prospect of losing their contracts, organizational culture and seniority-based salary where they become more dissatisfied and frustrated with the condition of work as a result of the changes in work environment. This will eventually lead them to quit their organizations, further, the emotional dissonance which is the difference between the real expressions anticipated from them and their feelings leads to declined job satisfaction and increased intention to leave their jobs [1].

Lately, difficult economic situation in many governments have caused a decline in the job satisfaction of public employees, triggering higher turnover intention and burnout. More precisely, this research examined the role of intrinsic and extrinsic motivation of public employees. Employees often show their discontent with the government institutions in terms of fulfilling their needs and aspirations. For instance, a stressful work environment may expressively impact revenue officers' turnover intention and burnout. As described by Bear, Slaughter, Mantz, \& Farley-ripple [2], the majority of public tax collectors complain from emotional exhaustion before they decide to quit their jobs because their

Revised Manuscript Received on September 25, 2019

Mohammed Matar, Faculty of Business and Accountancy, Lincoln University College, Selangor, Malaysia

Aldhaheri, Faculty of Business and Accountancy, Lincoln University College, Selangor, Malaysia

Mohammed Nussari, Faculty of Business and Accountancy, Lincoln University College, Selangor, Malaysia emotional and psychological needs must be fulfilled systemically to enhance their work performance and health.

In the current context, the public sector of Dubai has changed in scope over the last few years and continues to implement changes in a manner that is much is similar to the private sector in contemporary times. Turkyilmaz, Akman, Özkan, \& Pastuszak [3] mention that the UAE public sector seeks to enhance its employee performance through the focus on individuals in various sectors. As a result of this pressure to change, the public-sector organizations have shown an increased interest in adopting new management practices that will help achieve results in this regard.

\section{LiteratURE REVIEW}

\section{A. Employee Performance (EP)}

Employee performance is among the most important variables in the management research and arguably the most important indicator in determining the overall organizational performance [4]. It is the measure of standard or prescribed indicators of effectiveness, efficiency, and environmental responsibility such as, cycle time, productivity, waste reduction, and regulatory compliance. Employee performance is one of the ultimate dependent variables of interest by researchers whose concern on management study. This specific construct is essential in permitting researchers and managers to evaluate organizations over time and compare them to rivals [5]. In short, employee performance is the most important criterion in evaluating organizations, their actions, and environments. This importance is reflected in the pervasive use of employee performance as a dependent variable in previous research . [5].

\section{B. Organizational Motivation (OM)}

Intrinsic motivation is described as the need to do an activity for its own sake, for the purpose of experiencing the satisfaction and pleasure instilled in the activity. On the other hand extrinsic motivation is usually described as the need to do an activity with the aim to achieve positive values like incentive or to evade negative ones like punishment. Further, according to the self-determination theory, intrinsic motivation. Self-determination theory suggests that 
intrinsic motivation instigates from the individual's internal desire which leads to the enjoyment in increasing one's competency. Generally, fun, skill development, and self-achievement are recognized as the main intrinsic motivation players. Hence, two hypotheses were suggested:

H1. Intrinsic motivation significantly influences in a positive way on the performances of the staff of the organization.

H2. Extrinsic motivation significantly influences in a positive way on the performances of the staff of the organization..

Figure 1 shows the proposed study model which contain two independent variables (intrinsic motivation and extrinsic motivation) and one dependent variable (employee performance)

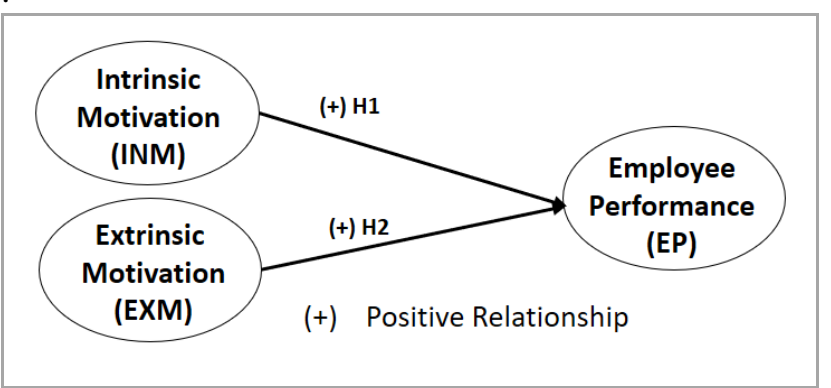

Fig. 1. The proposed conceptual framework

\section{RESEARCh DeSIGN AND Methodology}

\section{A. Instrument Development}

The development of an instrument for this study included a 15-item questionnaire, and based on the literature. The 5-pointer Likert's scale was used for analysis of the responses of the respondents. Given the fact that the respondents were Arabic-speakers, it is required to have the questionnaires translated from English to Arabic in a precise way. Thus a back translation was applied, which is a procedure widely used in a cross-cultural survey [6]. Previous studies were used to get a validated to measure the variables in this study as shown in Appendix A. The study item of each construct has been taken into consideration on the basis of the guidelines given by Hayduk \& Littvay [7].

\section{B. Data Collection}

The data was collected by delivering a self-administered questionnaires 'in-person' from April 2018 until August 2018 to government employees in Dubai. The number of the questionnaires that were considered suitable for the analysis was 732. According to Tabachnick \& Fidell [8] and Krejcie \& Morgan [9], the sample size was seen as sufficient.

\section{Data Analysis and Results}

SmartPLS 3.0 software was used to analyze the data of this study [10]. A two-stage analytical method [11,12] was used which comprising (i) measurement model assessment and (ii) structural model assessment.

\section{A. Descriptive analysis}

Extrinsic motivation score the highest with mean 3.850 out of 5.0, with a standard deviation of 0.989 . Employee performance score the lowest with mean 3.558 out of 5.0, with a standard deviation of 0.942 , as Table 1 shows.

\section{B. Measurement Model Assessment}

The individual Cronbach's alpha, the composite reliability (CR), The average variance extracted (AVE), and the factor loadings exceeded the suggested value $[13,14]$ as illustrated in Table 1

Table 1: Measurement assessment results

\begin{tabular}{|c|c|c|c|c|c|c|c|}
\hline Constructs & Item & $\begin{array}{c}\text { Loading } \\
(>0.5)\end{array}$ & M & SD & $\begin{array}{c}\alpha \\
(>0.7)\end{array}$ & $\begin{array}{c}\text { CR } \\
(>0.7)\end{array}$ & $\begin{array}{c}\text { AVE } \\
(>0.5)\end{array}$ \\
\hline \multirow{5}{*}{$\begin{array}{l}\text { Intrinsic } \\
\text { Motivation } \\
\text { (INM) }\end{array}$} & INM1 & 0.856 & \multirow{5}{*}{3.726} & \multirow{5}{*}{0.913} & \multirow{5}{*}{0.908} & \multirow{5}{*}{0.932} & \multirow{5}{*}{0.733} \\
\hline & INM2 & 0.896 & & & & & \\
\hline & INM3 & 0.913 & & & & & \\
\hline & INM4 & 0.816 & & & & & \\
\hline & INM5 & 0.793 & & & & & \\
\hline \multirow{4}{*}{$\begin{array}{c}\text { Extrinsic } \\
\text { Motivation } \\
(\text { EXM) }\end{array}$} & EXM1 & 0.925 & \multirow{4}{*}{3.850} & \multirow{4}{*}{0.989} & \multirow{4}{*}{0.922} & \multirow{4}{*}{0.945} & \multirow{4}{*}{0.812} \\
\hline & EXM2 & 0.924 & & & & & \\
\hline & EXM3 & 0.928 & & & & & \\
\hline & EXM4 & 0.821 & & & & & \\
\hline \multirow{6}{*}{$\begin{array}{c}\text { Employee } \\
\text { Performance } \\
\text { (EP) }\end{array}$} & EP1 & 0.899 & \multirow{6}{*}{3.558} & \multirow{6}{*}{1.019} & \multirow{6}{*}{0.942} & \multirow{6}{*}{0.953} & \multirow{6}{*}{0.771} \\
\hline & EP2 & 0.871 & & & & & \\
\hline & EP3 & 0.899 & & & & & \\
\hline & EP4 & 0.809 & & & & & \\
\hline & EP5 & 0.891 & & & & & \\
\hline & EP6 & 0.895 & & & & & \\
\hline
\end{tabular}

Note: $\mathrm{M}=$ Mean; $\mathrm{SD}=$ Standard Deviation, $\alpha=$ Cronbach's alpha; $\mathrm{CR}=$ Composite Reliability, AVE = Average Variance Extracted.

Key: IM: Intrinsic Motivation, EM: Extrinsic Motivation, EP: Employee Performance. 
The extent that items differentiate among constructs or measure distinct concepts is shown by Discriminant validity. The discriminant validity of the measurement model was assessed by utilizing the Cross-loadings and
Fornell-Larcker. Usually, cross-loadings are used as the first step in testing discriminant validity of the indicators [10]. The cross loading criterion was found to be in satisfaction with all the requirements of the study (refer to Table 2). Table 2: Cross loading Result

\begin{tabular}{l|ccc}
\hline & $I N M$ & $E X M$ & $E P$ \\
\hline INM1 & $\mathbf{0 . 8 5 6}$ & 0.395 & 0.469 \\
INM2 & $\mathbf{0 . 8 9 6}$ & 0.460 & 0.538 \\
INM3 & $\mathbf{0 . 9 1 3}$ & 0.470 & 0.544 \\
INM4 & $\mathbf{0 . 8 1 6}$ & 0.647 & 0.497 \\
INM5 & $\mathbf{0 . 7 9 3}$ & 0.694 & 0.498 \\
EXM1 & 0.538 & $\mathbf{0 . 9 2 5}$ & 0.395 \\
EXM2 & 0.526 & $\mathbf{0 . 9 2 4}$ & 0.423 \\
EXM3 & 0.589 & $\mathbf{0 . 9 2 8}$ & 0.484 \\
EXM4 & 0.579 & $\mathbf{0 . 8 2 1}$ & 0.436 \\
EP1 & 0.474 & 0.359 & $\mathbf{0 . 8 9 9}$ \\
EP2 & 0.415 & 0.368 & $\mathbf{0 . 8 7 1}$ \\
EP3 & 0.473 & 0.354 & $\mathbf{0 . 8 9 9}$ \\
EP4 & 0.382 & 0.342 & $\mathbf{0 . 8 0 9}$ \\
EP5 & 0.645 & 0.526 & $\mathbf{0 . 8 9 1}$ \\
\hline
\end{tabular}

Key: IM: Intrinsic Motivation, EM: Extrinsic Motivation, EP: Employee Performance.

Table 3 concludes that the square root of the AVEs on the diagonals (diagonally arranged) are more than the correlations between constructs. This further indicates that strong correlation between the constructs and their respective indicators as compared to the other constructs in the model [15,16]. Hence, a good discriminant validity with the exogenous constructs having a correlation value of less than 0.85 is evident from the study outcomes [10,17]. Therefore, all constructs had their discriminant validity fulfilled satisfactorily.
Table 3: Results of discriminant validity by Fornell-Larcker criterion

\begin{tabular}{l|lll}
\hline & EP & EXM & INM \\
\hline$E P$ & $\mathbf{0 . 8 7 8}$ & & \\
$E X M$ & 0.485 & $\mathbf{0 . 9 0 1}$ & \\
$I N M$ & 0.596 & 0.622 & $\mathbf{0 . 8 5 6}$ \\
\hline
\end{tabular}

Note: Diagonals represent the square root of the average variance extracted while the other entries represent the correlations.

Key: IM: Intrinsic Motivation, EM: Extrinsic Motivation, EP: Employee Performance.

The structural model can be tested by computing beta $(\beta)$, $\mathrm{R}^{2}$, and the corresponding t-values via a bootstrapping procedure with a resample of 5,000 [10].

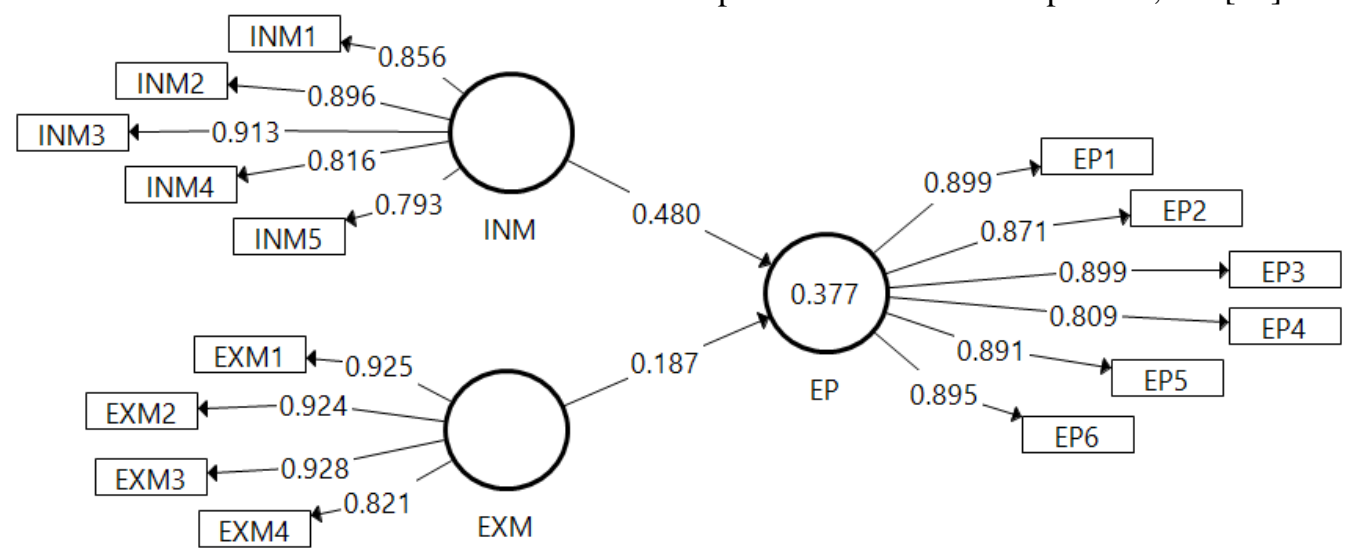

Key: IM: Intrinsic Motivation, EM: Extrinsic Motivation, EP: Employee Performance. Fig. 2: PLS algorithm results 
The structural model described above (Figure 2 and Table 4)shows the results of the hypothesis tests, with 2 out of the 2 hypotheses are supported. Intrinsic motivation and extrinsic motivation significantly predict employee performance. Hence, $\mathrm{H} 1$ and $\mathrm{H} 4$ are accepted with $(\beta=0.480, \mathrm{t}=187, \mathrm{p}<0.001)$ and $(\beta=0.187, \mathrm{t}=3.037, \mathrm{p}$ $<0.01)$ respectively.

The strength of the relationship between exogenous and endogenous constructs are measured by the standardised path coefficients, which in this case show that the direct effects of Intrinsic motivation on employee performance is much stronger than the influence of extrinsic motivation on employee performance.

Thirty-eight percent of the variance in employee performance is explained by intrinsic motivation and extrinsic motivation. The values of $\mathrm{R}^{2}$ have an acceptable level of explanatory power, indicating a substantial model $[18,19]$.

Table 4: Structural assessment results

\begin{tabular}{clllllll}
\hline \hline Hypothesis & Relationship & Std Beta & Std Error & t-value & p-value & Decision & $\mathrm{R}^{2}$ \\
\hline H1 & INM $\rightarrow$ EP & 0.480 & 0.055 & 8.754 & 0.000 & Supported & 0.38 \\
H2 & EXM $\rightarrow$ EP & 0.187 & 0.062 & 3.037 & 0.001 & Supported \\
\hline \hline
\end{tabular}

Key: IM: Intrinsic Motivation, EM: Extrinsic Motivation, EP: Employee Performance.

\section{Discussion And Conclusion}

The study found that intrinsic motivation positively affects employee performance in government sector in Dubai, this is supported by previous studies [20-22]. It is explained by the fact that the more the tasks are enjoyable, and employees perceive the job as meaningful, exciting, representing a driving power, very inspiring to the extent that employees forget everything else around them., the more the employees are fulfilling their responsibilites, meet all formal performance requirments, complete their duties, and are encouraged to work harder as a result of performance assessment.

Likewise, it was found that extrinsic motivation positively affects the internal process of organizations among employees in government sector in Dubai, this is supported by previous studies [2, 23, 24]. It is explained by the fact that the more the employees get an extra pay when putting more effort on job, and they think that it is important for them to have an external incentive to strive, the more the employees are fulfilling their responsibilites, meet all formal performance requirments, complete their duties, and are encouraged to work harder as a result of performance assessment.

This study represents a major foundation in elevating this concept of motivation within the Emirates public sector.

\section{APPENDIX}

Appendix A

Instrument for varibles
Therefore, this study has provided a comprehensive illustration of how the role of internal leadership practices relates to individuals, groups, and employee performance and how it can be used in the best way to enhance overall performance.

One limitation of this study is its population selection and future researchers could validate the model in more public sectors in the UAE, as well as different Arab countries. Besides, this study focused in the public sector and did not cover the private sector $[25,26]$.

This study examined only a few variables to predict employee performance, future research may include more variables to our model. For instance reward and recognition, job satisfaction and so forth. Can also be taken into account for future research. A comparative study among the employees of government different authorities is also suggested. Finally, the relationships proposed in this study could be tested using moderators such as gender or departments [27].

The results revealed that both hypotheses are significant. The independent variables significantly explain $37.7 \%$ of employee performance. The implications of this study have been discussed and some directions for future research have been suggested.

\begin{tabular}{cllll}
\hline Varible & \multicolumn{1}{c}{ Measure } & Source \\
\hline & INM1: The tasks that I do at work are enjoyable. & \\
INM2: My job is meaningful & & \\
Intrinsic & INM3: My job is very exciting. \\
Motivation & INM4: The tasks that I do at work are themselves \\
(INM) & representing a driving power in my job. & \\
& INM5: Sometimes I become so inspired by my job that I \\
& almost forget everything else around me.
\end{tabular}


Extrinsic

Motivation

(EXM)

Employee

Performance

(EP)
EXM1: I get extra pay when I put in extra effort into my

job.

EXM2: I get incentives when $I$ do a better job.

EXM3: It is important for me to have an external incentive to strive for in order to do a good job.

EXM4: External incentives such as bonuses and provisions are essential for how well I perform my job.

EP1: The current level of staff productivity is high.

EP2: The employee productivity level of the organization is

high.

EP3: The employee fulfills all responsibilities required by their job.

EP4: The employee meets all formal performance requirements of the job.

EP5: The employee completes the duties specified in their job description.

EP6: Performance assessment makes me work hard.

\section{REFERENCES}

[1] G. G. Bear, J. C. Slaughter, L. S. Mantz \& E. Farley-ripple, (2017). Rewards, praise, and punitive consequences : Relations with intrinsic and extrinsic motivation. Teaching and Teacher Education, vol. 65, pp. 10-20. https://doi.org/10.1016/j.tate.2017.03.001

[2] H. Liang, M. Wang, J. Wang \& Y. Xue, (2018). How intrinsic motivation and extrinsic incentives affect task effort in crowdsourcing contests: A mediated moderation model. Computers in Human Behavior, 81, pp. 168-176. https://doi.org/10.1016/j.chb.2017.11.040

[3] Turkyilmaz, G. Akman, C. Özkan, \& Z. Pastuszak, (2011). Empirical Study of Public Sector Employee Loyalty and Satisfaction. Industrial Management and Data Systems, 111.

[4] Gavrea, L. Ilies \& R. Stegerean (2011). Determinants of organizational performance: The case of Romania. Management \& Marketing, 6(2), pp. 285-300.

[5] P. J. Richard, T. Devinney, G. Yip \& G. Johnson, (2009). Measuring Organizational Performance: Towards Methodological Best Practice. $\begin{array}{llll}\text { Journal of } & \text { Management } & \text { Vol. } & \end{array}$ https://doi.org/10.1177/0149206308330560

[6] R. W. Brislin, (1970). Back-Translation for Cross-Cultural Research. Journal of Cross-Cultural Psychology Vol. 1. Brislin. https://doi.org/10.1177/135910457000100301

[7] L. A. Hayduk \& L. Littvay (2012). Should researchers use single indicators, best indicators, or multiple indicators in structural equation models? BMC Medical Research Methodology, 12(1), pp. 1-17. https://doi.org/10.1186/1471-2288-12-159

[8] B. G. Tabachnick \& L. S. Fidell, (2012). Using Multivariate Statistics (6th ed.). Pearson.

[9] R. V Krejcie \& D. W. Morgan (1970). Determining sample size for research activities. Educational and Psychological Measurement, 38, pp. 607-610.

[10] C. M. Ringle, S. Wende \& J.-M. Becker, (2015). SmartPLS 3. Bonningstedt: SmartPLS.

[11] J. C. Anderson \& D. W. Gerbing (1988). Structural Equation Modeling in Practice: A Review and Recommended Two-Step Approach. Psychological Bulletin, 103(3), pp. 411-423.

[12] J. F. Hair, G. T. M. Hult, C. Ringle \& M. Sarstedt, (2017). A Primer on Partial Least Squares Structural Equation Modeling (PLS-SEM) (2nd ed.). London: Thousand Oaks: SAGE.

[13] R. B. Kline, (2010). Principles and practice of structural equation modeling (3rd ed.). New York: The Guilford Press.

[14] J. F. Hair, W. C. Black, B. J. Babin \& R. E. Anderson (2010). Multivariate Data Analysis (7th ed.). New Jersey: Pearson.

[15] C. Fornell \& D. F. Larcker, (1981). Evaluating structural equation models with unobservable variables and measurement error. Journal of Marketing Research, 18(1), pp. 39-50.

[16] W. W. Chin (1998a). Issues and opinion on structural equation modeling. MIS Quarterly, 22(1), pp. 7-16.

[17] Z. Awang (2014). Structural Equation Modeling Using AMOS. Shah Alam.Malaysia: University Teknologi MARA Publication Center.

[18] J. Cohen, (1988). Statistical Power Analysis for the Behavioral Sciences (2nd ed.). London: Routledge.

[19] W. W. Chin (1998b). The partial least squares approach to structural equation modeling. In G. A. Marcoulides (Ed.), Modern methods for business research (pp. 295-358). New Jersey: Lawrence Erlbaum Associates. Mahwah, NJ: Lawrence Erlbaum.

[20] M. S. Lemos, \& L. Veríssimo, (2014). The relationships between intrinsic motivation, extrinsic motivation, and achievement , along elementary school. Procedia - Social and Behavioral Sciences, 112(Iceepsy 2013), pp. 930-938 https://doi.org/10.1016/j.sbspro.2014.01.1251

[21] Y. Li, K. M. Sheldon \& R. Liu, (2015). Dialectical thinking moderates the effect of extrinsic motivation on intrinsic motivation. Learning and Individual Differences, 39, pp. 89-95. https://doi.org/10.1016/j.lindif.2015.03.019

[22] I. Vilnai-yavetz \& O. Levina, (2018). Motivating social sharing of e-business content: Intrinsic motivation, extrinsic motivation, or crowding-out effect? Computers in Human Behavior, 79, pp. 181-191. https://doi.org/10.1016/j.chb.2017.10.034

[23] B. Kuvaas, R. Buch, A. Weibel, A. Dysvik \& C. G. L. Nerstad, (2017) Do intrinsic and extrinsic motivation relate differently to employee outcomes? Journal of Economic Psychology, 61, pp. 244-258 https://doi.org/10.1016/j.joep.2017.05.004 